\title{
The Graft Thickness in Descemet Stripping Automated Endothelial Keratoplasty: What Is the Importance to the Final Visual Outcome?
}

\author{
Diana Cristóvão ${ }^{1 *}$, Ana Fonseca ${ }^{1}$, Nuno Alves ${ }^{2}$, Vítor Maduro², João Feijão², Pedro Candelária² \\ ${ }^{1}$ Instituto de Oftalmologia Dr. Gama Pinto (IOGP), Lisbon, Portugal \\ ${ }^{2}$ Centro Hospitalar de Lisboa Central (CHLC), Lisbon, Portugal \\ Email: *dmc9339@gmail.com
}

How to cite this paper: Cristóvão, D., Fonseca, A., Alves, N., Maduro, V., Feijão, J. and Candelária, P. (2017) The Graft Thickness in Descemet Stripping Automated Endothelial Keratoplasty: What Is the Importance to the Final Visual Outcome? Open Journal of Ophthalmology, 7, 167-175. https://doi.org/10.4236/ojoph.2017.73023

Received: June 2, 2017

Accepted: July 9, 2017

Published: July 12, 2017

Copyright $\odot 2017$ by authors and Scientific Research Publishing Inc. This work is licensed under the Creative Commons Attribution International License (CC BY 4.0).

http://creativecommons.org/licenses/by/4.0/

(c) † Open Access

\begin{abstract}
Introduction: Descemet Stripping Automated Endothelial Keratoplasty (DSAEK) is currently considered the procedure of choice for the treatment of endothelial dysfunctions. Despite DSAEK being a promising procedure to improve visual acuity (VA), the ideal graft thickness donor still remains under discussion. Purpose: To analyze the influence of graft thickness on postoperative VA and complications in DSAEK surgery. Methods: Retrospective study of 112 eyes that underwent DSAEK surgery. Donor grafts were obtained by dissection with automatic microkeratome, using different head sizes. Central corneal thickness (CCT) of donor corneas before dissection was measured by ultrasound pachymetry. The choice of the cutting depth was based on CCT measurements and the final desired residual corneal thickness, corresponding to the estimated donor graft thickness (EDGT). The eyes were divided into 3 groups, depending on the EDGT: $<180 \mu \mathrm{m}$ (Group 1), 180 - $200 \mu \mathrm{m}$ (Group 2) and $>200 \mu \mathrm{m}$ (Group 3). Intraoperative, postoperative complications and the best corrected visual acuity (BCVA) at 6 months postoperatively were evaluated, comparing these 3 groups. Results: The average EDGT was $164 \pm 10$ $\mu \mathrm{m}$ in Group $1188 \pm 7 \mu \mathrm{m}$ in Group 2 and $234 \pm 30 \mu \mathrm{m}$ in Group 3. At 6 months postoperative the average BCVA was significantly better in Group 1 (BCVA: $0.74 \pm 0.20$ ), compared to Group 2 (BCVA: $0.54 \pm 0.20$ ) and Group 3 (BCVA: $0.39 \pm 0.18$ ). Intraoperative and postoperative complications included: graft perforation during cutting ( $0.9 \%$ of cases), graft rejection (3.6\%), primary graft failure (4.5\%), and graft detachment (3.6\%). Its distribution was uniform between the 3 groups. Conclusion: The study proves that DSAEK is an effective surgical technique for the treatment of endothelial dysfunction, demonstrating that the use of thinner grafts (EDGT $<180 \mu \mathrm{m})$ can improve the final visual outcome, with a significant improvement on BCVA, without increasing the risk of complications.
\end{abstract}




\section{Keywords}

DSAEK, Graft Thickness, Visual Acuity, Complications

\section{Introduction}

DSAEK (Descemet Stripping Automated Endothelial Keratoplasty) is a type of posterior lamellar transplantation surgery of the cornea that allows a selective replacement of the pathological corneal endothelium and it can be characterized as a minimally invasive procedure [1] [2]. It is currently considered the procedure of choice for the treatment of endothelial corneal diseases, such as Fuchs endothelial dystrophy or pseudophakic bullous keratopathy and it has largely replaced penetrating keratoplasty in the treatment of those diseases [1]-[6].

In DSAEK surgery, the corneal graft is obtained from automated mode using the automatic microkeratome. The corneal graft or lenticule consists of posterior stroma lamella, Descemet membrane and endothelium. The cut depth is determined by the cutting head size used [1] [3] [6].

DSAEK offers many advantages over penetrating keratoplasty: it provides better tectonic stability, minimal induced astigmatism, early refractive stability, faster visual recovery, and reduced intraoperative and postoperative complications [1] [3] [6] [7].

Although there is no questioning about the effectiveness of DSAEK surgery, with most patients achieving a best corrected visual acuity (BCVA) of 20/40 or better, there has been an ongoing discussion regarding the cause for only a relatively small percentage of patients achieve BCVA of 20/20, despite completely transparent corneas in the postoperative period. In general, there are two main hypotheses to explain this phenomenon. The first hypothesis is that the stromato-stroma interface is a problem that somehow results in optical degradation. The second hypothesis is that the added stromal thickness itself is what degrades the vision and simultaneously leads to greater morphological changes of posterior corneal curvature with a greater refractive shift [5].

Even though isolated transplantation of Descemet membrane and endothelium performed at DMEK surgery (Descemet membrane endothelial keratoplasty) demonstrates superior visual outcomes compared to the DSAEK procedure, this technique is currently limited by the high surgical complexity (technical difficulty of preparation and handling of the lenticule, with a high risk of substantial endothelial cells loss) and higher postoperative complication rates, including lenticule detachment and iatrogenic primary failure [5] [6].

In an attempt to improve the visual outcomes of DSAEK surgery and at the same time keep the reduced complication rates, several aspects of this procedure have been refined, and recently the attention has been turned to the graft thickness [6]. Thus, several studies have sought to demonstrate if the donor graft thickness influences the final visual outcome. Some recent studies suggest that thinner grafts may be associated with a better visual outcome [1] [2] [4] [7]. 
However, other studies found no correlation between graft thickness and vision [3] [5] [8] [9].

Due to the lack of clear evidence to support the use of thinner grafts in DSAEK procedure, the purpose of this study was to analyze the influence of graft thickness in visual acuity and in intraoperative and postoperative complications rates.

\section{Materials and Methods}

This is a retrospective study of 112 eyes with bullous keratopathy who underwent DSAEK surgery in Centro Hospitalar Lisboa Central (CHLC) between January 2014 and December 2015. Local research ethics committee approval was obtained, and the study adhered to the tenets of the Declaration of Helsinki.

The donor corneas were mounted on an artificial anterior chamber. The pressure in the system was standardized by raising the infusion bottle to a height of $180 \mathrm{~cm}$ above the level of the artificial anterior chamber and then clamping the tube at $50 \mathrm{~cm}$ from the entrance into the chamber.

The donorlenticules were prepared from the donor corneas by a single-pass dissection with an automated microkeratome (MORIA ${ }^{\circledR}$ ), using different cutting heads $(300 \mu \mathrm{m}, 350 \mu \mathrm{m}, 400 \mu \mathrm{m}$ or $450 \mu \mathrm{m})$. Prior to the microkeratome cut, the central corneal thickness (CCT) of the donor corneas were measured by ultrasound pachymetry, subsequent to epithelial removal.

The choice of the cutting depth was based on CCT measurement's and the final desired residual corneal thickness that corresponds to the estimated donor graft thickness (EDGT).

Pachymetry was performed to all corneas before the cutting procedure to determine the real tissue thickness and choose the appropriate microkeratome head(s). Thickness measurements were taken and an average of 5 pachymetry readings was calculated.

The tissue remained mounted on the artificial anterior chamber. Microkeratome dissection was made using a 300- to 450-microkeratome head, depending on the tissue thickness, with the goal of ultimately creating a graft with a desired thickness of approximately $150 \mu \mathrm{m}$. Thus, the CCT was used to select the cutting head size predicted to achieve the desired graft thickness.

The donor lenticules were then placed on a Teflon block with endothelial side up and trephined using an appropriately sized corneal trephine ( 8.0 or $8.5 \mathrm{~mm})$.

DSAEK surgeries were performed by one of four experienced surgeons, and in all of them was used the following surgical technique: a nasal $4.5 \mathrm{~mm}$ and temporal $1.5 \mathrm{~mm}$ incisions were made in the clear cornea at 3 and 9 o'clock; a 1.5 $\mathrm{mm}$ incision was made in the clear cornea at 6 o'clock to the anterior chamber maintainer infusion line filled with balanced salt solution; a "T" shaped DSAEK stripper was used to remove the host endothelium and Descemet membrane along the circumference corresponding to the epithelial $9 \mathrm{~mm}$ ring mark; it was also performed a peripheral iridectomy at 6 o'clock; the donor lenticule was introduced in the anterior chamber and the coaptation of the lenticule was made 
to the host posterior corneal stroma with an air bubble.

The main exclusion criteria from this analysis were patients with significant ocular comorbidities, which could affect the final visual acuity, such as severe glaucoma, retinal macular diseases and amblyopia or patients submitted to other previous intraocular surgeries, except for cataract surgery with intraocular lens implant.

The eyes were divided into 3 groups, depending on the EDGT: $<180 \mu \mathrm{m}$ (Group 1), 180 to $200 \mu \mathrm{m}$ (Group 2) and $>200 \mu \mathrm{m}$ (Group 3). Intraoperative and postoperative complications, preoperative BCVA and BCVA at 6 months postoperatively were evaluated, comparing the 3 groups of this study. Visual acuity evaluation was performed using standard Snellen chart (decimal scale).

All the collected data were analyzed using SPSS version 23 (IBM Corp., Armonk, NY). The quantitative data were expressed as average \pm SD and qualitative data were expressed as a percentage. The statistical significance of quantitative variables was determined by paired Student $t$ test or univariate analysis of variance (one-way ANOVA). In the comparison between one pair of groups with one-way ANOVA, when the test result was significant, the pair of groups were compared by post-hoc tests (Student $t$ test) with Bonferroni's correction. For comparing the statistical significance of categorical variables, the $\chi^{2}$ test was applied. A p value $<0.001$ was considered as the indication of statistical significance. The Pearson correlation coefficient was performed to analyze the correlation between variables.

\section{Results}

This study analyzed a total of 112 eyes from 95 patients, who were treated with DSAEK surgery. These eyes were divided into 3 groups, depending on the EDGT: <180 $\mu \mathrm{m}$ (Group 1), 180 to $200 \mu \mathrm{m}$ (Group 2) and >200 $\mu \mathrm{m}$ (Group 3). Group 1 included 37 eyes, Group 2 included 36 eyes and Group 3 included 39 eyes. The average EDGT was $164 \pm 10 \mu \mathrm{m}, 188 \pm 7 \mu \mathrm{m}$ and $234 \pm 30 \mu \mathrm{m}$ in Group 1, Group 2 and Group 3, respectively (Table 1). Statistically there was no significant difference between the 3 groups with regards to the age, gender and preoperative BCVA ('Table 2).

Six months after endothelial transplantation, the 3 groups showed a significant improvement in BCVA $(\mathrm{P}<0.001)$. In Table 3 are presented the preoperative and postoperative BCVA according to the donor graft thickness.

Table 1. Comparison of donor graft estimated thickness (EDGT) between the 3 study groups.

\begin{tabular}{cccc}
\hline & EDGT, interval $(\mu \mathrm{m})$ & EDGT, average \pm SD $(\mu \mathrm{m})$ & Number of eyes, N \\
\hline Group 1 & $140-178$ & $164 \pm 10$ & 37 \\
Group 2 & $180-200$ & $188 \pm 7$ & 36 \\
Group 3 & $203-310$ & $234 \pm 30$ & 39 \\
Total & $140-310$ & $196 \pm 35$ & 112 \\
\hline
\end{tabular}


Table 2. Baseline demographics of patients that underwent DSAEK surgery.

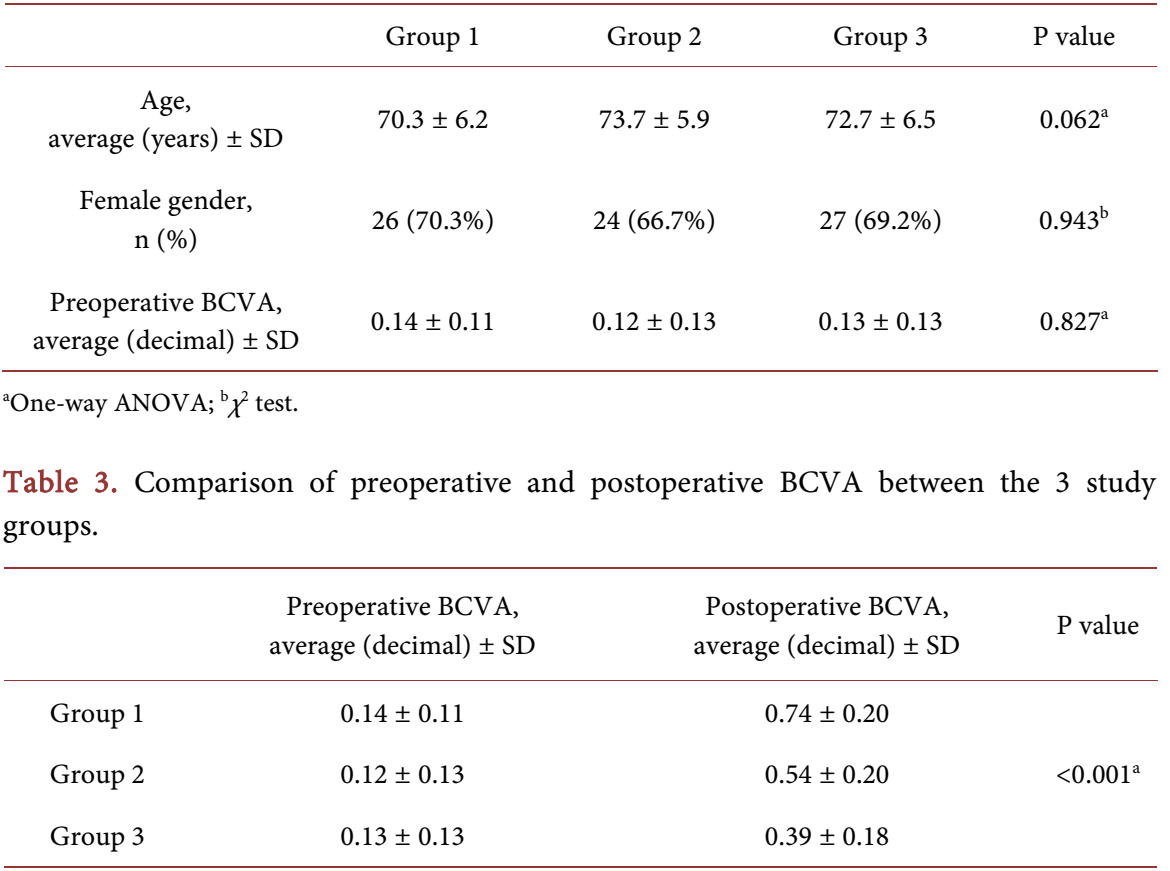

${ }^{\text {aStudent }} \mathrm{t}$ test.

Table 4. Preoperative BCVA, postoperative BCVA, and difference between preoperative and postoperative BCVA: comparative study of the 3 groups.

\begin{tabular}{ccccc}
\hline & Group 1 & Group 2 & Group 3 & P value $^{*}$ \\
\hline $\begin{array}{c}\text { Preop. BCVA, } \\
\text { average (decimal) } \pm \text { SD }\end{array}$ & $0.14 \pm 0.11$ & $0.12 \pm 0.13$ & $0.13 \pm 0.13$ & 0.827 \\
$\begin{array}{c}\text { Postop. BCVA, } \\
\text { average (decimal) } \pm \text { SD } \\
\begin{array}{c}\text { Difference } \\
\text { Preop.-Postop. BCVA } \\
\text { average (decimal) } \pm \text { SD }\end{array}\end{array}$ & $0.74 \pm 0.20^{\mathrm{a}}$ & $0.54 \pm 0.20^{\mathrm{b}}$ & $0.39 \pm 0.18^{\mathrm{c}}$ & $<0.001$ \\
\hline
\end{tabular}

*Comparison between groups (One-way ANOVA). The presence of a different letter in superscript indicates a significant difference between the pair of groups (post-hoc tests with Bonferroni's correction).

The postoperative BCVA was significantly better $(\mathrm{P}<0.001)$ in Group 1 (BCVA: $0.74 \pm 0.20$ ), compared to Group 2 (BCVA: $0.54 \pm 0.20$ ) and Group 3 (BCVA: $0.39 \pm 0.18$ ). The difference between preoperative and postoperative BCVA was $0.60 \pm 0.10$ in Group 1, $0.42 \pm 0.09$ in Group 2 and $0.26 \pm 0.06$ in Group 3 (Table 4 and Figure 1).

A Pearson correlation analysis was performed to determine if there was a statistically significant relationship between 6-month postoperative BCVA and donor graft thickness (EDGT). This analysis demonstrated a moderate negative statistically significant correlation indicating a worse postoperative BCVA with an increasing graft thickness $(\mathrm{r}=-0.54, \mathrm{P}<0.001$; Table 5 and Figure 2).

Intraoperative and postoperative complications obtained included: corneal perforation during the cut, which was registered in only 1 patient $(0.9 \%)$; graft rejection that occurred in 4 eyes (3.6\%), primary graft failure found in 5 eyes 


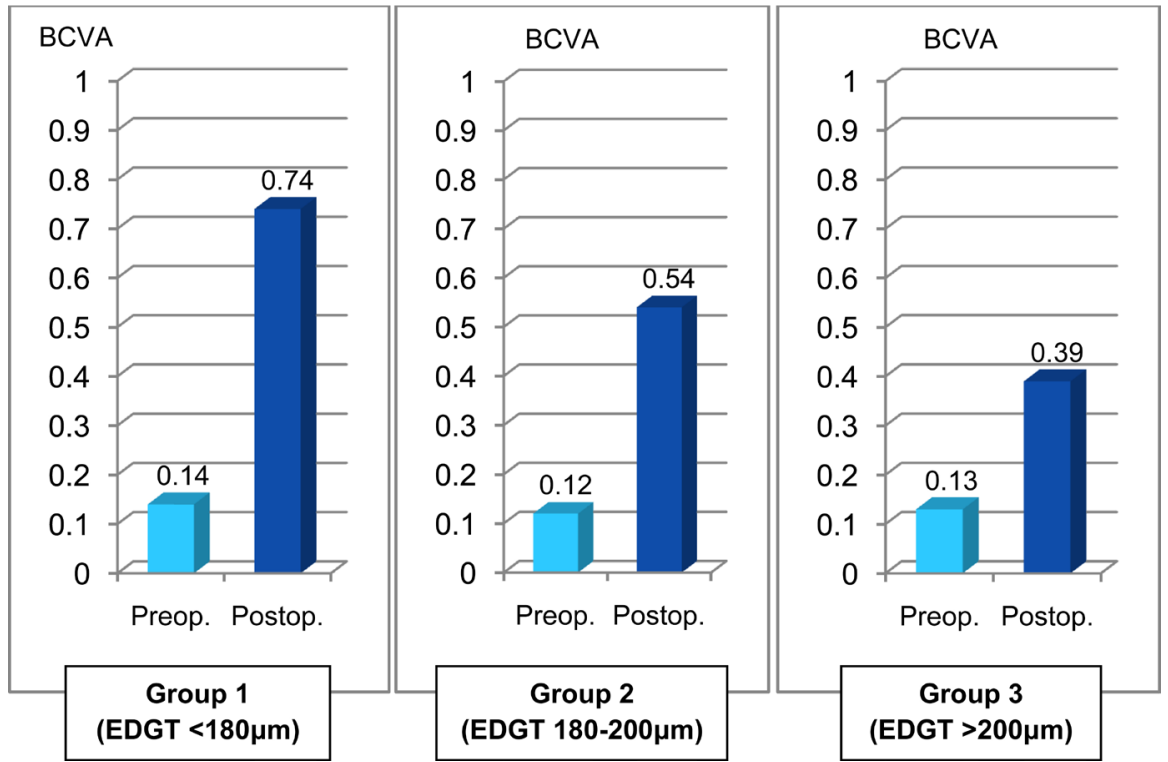

Figure 1. Preoperative and postoperative BCVA: Comparison of the 3 study groups.

Table 5. Analysis of Pearson correlation coefficient (r), concerning the relationship between postoperative BCVA and donor graft thickness (EDGT), for the study population.

\begin{tabular}{cc}
\hline & Total $(\mathbf{n}=112)$ \\
\hline EDGT, average $(\mu \mathrm{m})$ & 196 \\
Postop. BCVA, average $($ decimal $) \pm \mathrm{SD}$ & $0.56 \pm 0.24$ \\
EDGT variance & 1237.52 \\
Postop. BCVA variance & 0.06 \\
Covariance & -4.64 \\
Pearson $\mathrm{r}$ & -0.54 \\
P value & $<0.001$ \\
\hline
\end{tabular}

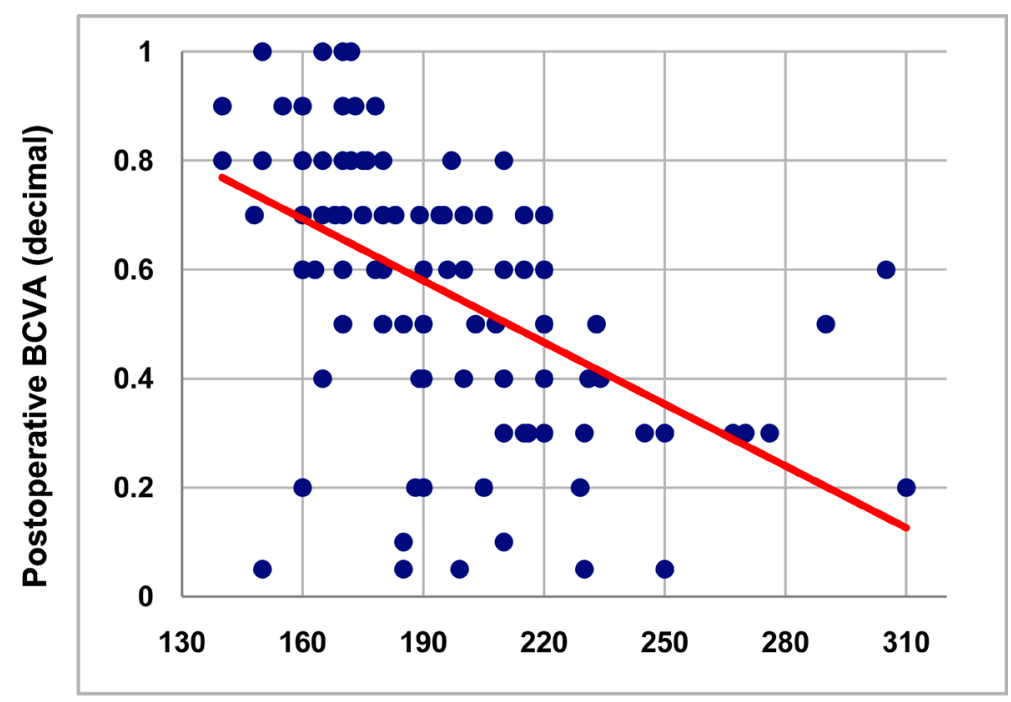

EDGT ( $\mu \mathrm{m})$

Figure 2. Graphic representation of Pearson correlation between postoperative BCVA and donor graft thickness (EDGT), for the study population. 
Table 6. Intraoperative and postoperative complications.

\begin{tabular}{ccccc}
\hline & $\begin{array}{c}\text { Corneal perforation, } \\
\mathrm{n}(\%)\end{array}$ & $\begin{array}{c}\text { Graft rejection, } \\
\mathrm{n}(\%)\end{array}$ & $\begin{array}{c}\text { Primary graft } \\
\text { failure, } \mathrm{n}(\%)\end{array}$ & $\begin{array}{c}\text { Graft detachment, } \\
\mathrm{n}(\%)\end{array}$ \\
\hline Group 1 $(\mathrm{n}=37)$ & $1(2.7)$ & $1(2.8)$ & $1(2.7)$ & $1(2.7)$ \\
Group 2 $(\mathrm{n}=36)$ & $0(0)$ & $1(2.8)$ & $2(5.6)$ & $1(2.8)$ \\
Group 3 $(\mathrm{n}=39)$ & $0(0)$ & $2(5.1)$ & $2(5.1)$ & $2(5.1)$ \\
Total & $1(0.9)$ & $4(3.6)$ & $5(4.5)$ & $4(3.6)$ \\
\hline
\end{tabular}

(4.5\%) and 4 cases of graft detachment (3.6\%). Surgical complications were evenly distributed over the 3 groups (Table 6).

\section{Discussion}

DSAEK is currently the procedure of choice for the treatment of endothelial corneal diseases. Compared to penetrating keratoplasty, the main advantages include: better tectonic stability, less induced astigmatism, early refractive stability, faster visual recovery and reduction of intraoperative and postoperative complications [3] [6] [7].

In an attempt to improve the visual outcomes in DSAEK, several studies have sought to demonstrate the influence of donor graft thickness on visual acuity, even though the results are still not completely consensual. Some studies suggest that thinner lenticules may be associated with a better visual outcome [1] [2] [4] [7]. On the other hand, other studies found no correlation between the graft thickness and visual acuity [3] [5] [8] [9].

The current study demonstrated that DSAEK significantly improved the visual acuity in patients of all the 3 groups analyzed. This result is consistent with the previous studies [1]-[9], confirming the effectiveness of this surgical technique in the treatment of endothelial pathologies.

The visual improvement was significantly better in transplants made with "thinner" grafts (Group 1), with a postoperative BCVA of $0.74 \pm 0.20$, compared to transplants performed with "medium-thickness" grafts (Group 2) and "thicker" grafts (Group 3), which had a postoperative BCVA of $0.54 \pm 0.20$ and $0.39 \pm$ 0.18 , respectively.

There was no statistically significant difference between the 3 groups regarding age, gender and preoperative BCVA.

A Pearson correlation analysis was performed on the study population demonstrating a moderate negative statistically significant correlation between 6month postoperative BCVA and donor graft thickness, indicating a worse postoperative BCVA with an increasing graft thickness.

The intraoperative and postoperative complications obtained in this study were evenly distributed over the 3 groups and included: corneal perforation ( $0.9 \%$ of cases); graft rejection (3.6\%), primary graft failure (4.5\%) and graft detachment (3.6\%).

There are several limitations in our study. First of all, the graft thickness was 
calculated based on an estimative, through the difference between the CCT measurement obtained by ultrasound pachymetry and the depth of cut performed according to the cutting head used during graft preparation. Ideally, in order to obtain a precise measurement of graft thickness, it must be carried out an anterior segment optical coherence tomography (AS-OCT), during the postoperative period. A prospective study could evaluate the correlation between EDGT (calculated during graft preparation) and the thickness measured in the postoperative period using AS-OCT. Secondly, DSAEK surgery was performed by four different surgeons, which might involve subtle differences in surgical technique, preferences and management. Another limitation is the fact that the population analyzed is not homogeneous, including patients with both Fuchs dystrophy and bullous keratopathy, which influences different visual prognosis from the outset. Furthermore, this is a retrospective review and there are some inherent limitations that cannot be avoided, such as: some patients lose the monitoring by abandonment or opt for alternative ophthalmologic consultations; some data from eye examination and results from complementary diagnostic exams are not always available for all patients. Therefore it would be pertinent to perform a prospective study, more comprehensive and including other possible variables such as endothelial cell count, spherical equivalent, keratometric astigmatism, intraocular pressure and contrast sensitivity.

\section{Conclusion}

In conclusion, our study showed that DSAEK is an effective surgical technique in the treatment of endothelial dysfunction, demonstrating that the use of thinner grafts $(E D G T<180 \mu \mathrm{m})$ can improve the final visual outcome, with a significant increase in BCVA without increasing the risk of complications. However, remains to be determined what will be the ideal graft thickness that is simultaneously effective and safe. Therefore, more prospective studies are still needed.

\section{References}

[1] Acar, B.T., Akdemir, M.O. and Acar, S. (2014) Visual Acuity and Endothelial Cell Density with Respect to the Graft Thickness in Descemet's Stripping Automated Endothelial Keratoplasty: One Year Results. International Journal of Ophthalmology, 7, 974-979.

[2] Pogorelov, P., Cursiefen, C., Bachman, B.O. and Kruse, F.E. (2009) Changes in Donor Corneal Lenticule Thickness after Descemet's Stripping Automated Endothelial Keratoplasty (DSAEK) with Organ-Cultured Corneas. British Journal of Ophthalmology, 93, 825-829. https://doi.org/10.1136/bjo.2008.147389

[3] Daoud, Y.J., Munro, A.D., Delmonte, D.D., Stinnett, S., Kim, T., Carlson, A.N. and Afshari, N.A. (2013) Effect of Cornea Donor Graft Thickness on the Outcome of Descemet Stripping Automated Endothelial Keratoplasty Surgery. American Journal of Ophthalmology, 156, 860-866. https://doi.org/10.1016/j.ajo.2013.06.030

[4] Neff, K., Biber, J.M. and Holland, E.J. (2011) Comparison of Central Corneal Graft Thickness to Visual Acuity Outcomes in Endothelial Keratoplasty. Cornea, 30, 388391. https://doi.org/10.1097/ICO.0b013e3181f236c6

[5] Phillips, P.M., Phillips, L.J. and Maloney, C.M. (2013) Preoperative Graft Thickness 
Measurements Do Not Influence Final BSCVA or Speed of Vision Recovery after Descemet Stripping Automated Endothelial Keratoplasty. Cornea, 32, 1423-1427. https://doi.org/10.1097/ICO.0b013e3182a40689

[6] Roberts, H.W., Mukherjee, A., Aichner, H. and Rajan, M.S. (2015) Visual Outcomes and Graft Thickness in Microthin DSAEK: One-Year Results. Cornea, 34, 1345 1350. https://doi.org/10.1097/ICO.0000000000000596

[7] Jain, S., Sharma, N., Maharana, P.K., Agarwal, T., Sinha, R. and Vajpayee, R.B. (2016) Comparative Evaluation of Use of 400- $\mu \mathrm{m}$ and 350- $\mu \mathrm{m}$ Microkeratome Head to Prepare Donor Tissue in Cases of Descemet Stripping Automated Endothelial Keratoplasty. Eye Contact Lens, 43, 130-134.

[8] Shinton, A.J., Tsatsos, M., Konstantopoulos, A., Goverdhan, S., Elsahn, A.F., Anderson, D.F. and Hossain, P. (2012) Impact of Graft Thickness on Visual Acuity after Descemet's Stripping Endothelial Keratoplasty. British Journal of Ophthalmology, 96, 246-249. https://doi.org/10.1136/bjophthalmol-2011-300462

[9] Wisse, R.P., Achterberg, J.A. and Van der Lelij, A. (2014) DSAEK: Practical Approach to Choose the Microkeratome Head on the Basis of Donor Cornea Pachymetry. Cornea, 33, 230-234. https://doi.org/10.1097/ICO.0000000000000042

\section{Scientific Research Publishing}

Submit or recommend next manuscript to SCIRP and we will provide best service for you:

Accepting pre-submission inquiries through Email, Facebook, LinkedIn, Twitter, etc. A wide selection of journals (inclusive of 9 subjects, more than 200 journals)

Providing 24-hour high-quality service

User-friendly online submission system

Fair and swift peer-review system

Efficient typesetting and proofreading procedure

Display of the result of downloads and visits, as well as the number of cited articles

Maximum dissemination of your research work

Submit your manuscript at: http://papersubmission.scirp.org/

Or contact ojoph@scirp.org 